\title{
Mo2TiAlC2: A new ordered layered ternary carbide
}

\author{
Babak Anasori, Joseph Halim, Jun Lu, Cooper A. Voigt, Lars Hultman and Michel W. \\ Barsoum
}

\section{Linköping University Post Print}

\section{Tweet}

N.B.: When citing this work, cite the original article.

Original Publication:

Babak Anasori, Joseph Halim, Jun Lu, Cooper A. Voigt, Lars Hultman and Michel W. Barsoum, Mo2TiAlC2: A new ordered layered ternary carbide, 2015, Scripta Materialia, (101), $5-7$.

http://dx.doi.org/10.1016/j.scriptamat.2014.12.024

Copyright: Elsevier http://www.elsevier.com/

Postprint available at: Linköping University Electronic Press http://urn.kb.se/resolve?urn=urn:nbn:se:liu:diva-117200 


\title{
$\mathrm{Mo}_{2} \mathrm{TiAlC}_{2}$ : A New Ordered Layered Ternary Carbide
}

Babak Anasori ${ }^{1 *}$, Joseph Halim ${ }^{1,2},{\mathrm{Jun} \mathrm{Lu}^{2} \text {, Cooper A. Voigt }}^{1}$, Lars Hultman $^{2}$ and Michel W. Barsoum ${ }^{1}$

${ }^{1}$ Department of Materials Science \& Engineering, Drexel University, Philadelphia, PA 19104,USA

${ }^{2}$ Thin Film Physics Division, Department of Physics, Chemistry and Biology (IFM), Linköping University, SE-581 83 Linköping, Sweden

* Corresponding author. Tel.: +1 267217 2185. E-mail: anasori@ drexel.edu

\begin{abstract}
Herein we report on the synthesis of a new layered ternary carbide, viz.

$\mathrm{Mo}_{2} \mathrm{TiAlC}_{2}$, that was synthesized by heating an elemental mixture at $1600{ }^{\circ} \mathrm{C}$ for $4 \mathrm{~h}$ under Ar flow. Its lattice parameters were calculated via Rietveld analysis of powder Xray diffraction patterns to be $2.997 \AA$ and $18.661 \AA$. High-resolution scanning transmission electron microscopy further showed that this phase is ordered, with the Ti layers sandwiched between two Mo layers in a $\mathrm{M}_{3} \mathrm{AX}_{2}$ type layered ternary carbide structure.
\end{abstract}

Keywords: Ordered MAX phases, Ternary carbides 
The MAX phases are a large family of hexagonal, ternary, carbides and nitrides with a general formula $\mathrm{M}_{\mathrm{n}+1} \mathrm{AX}$, $(\mathrm{MAX})$ where $\mathrm{n}=1,2,3$ etc., $\mathrm{M}$ is an early transition metal (Sc, Ti, Zr, Hf, V, Nb, Ta, Cr, Mo and etc.), A is a group 13 to 16 element (Al, Ga, In, Tl, Si, Ge, Sn, Pb, P, As etc.) and X is carbon and/or nitrogen [1-3]. These phases combine some of the best attributes of metals and ceramics, which can be attributed to their thermodynamically nanolaminated layered structure and the metal-like nature of their bonding. Like metals, they are electrically and thermally conductive, most readily machinable $[4,5]$, not susceptible to thermal shock, plastic at high temperatures, and exceptionally damage tolerant [6]. Like ceramics, some of them are elastically rigid (Young's moduli $>300 \mathrm{GPa})$, lightweight $\left(\approx 4 \mathrm{Mg} / \mathrm{m}^{3}\right)$, maintain their strengths to high temperatures [1, 3] and some of them are creep and oxidation resistant [7-10].

Among the more than $70+$ different MAX phases that have been synthesized to date, some of the Al-containing ones, notably $\mathrm{Ti}_{2} \mathrm{AlC}$, have attracted the most attention due to their exceptional oxidation resistance as a result of thin protective alumina layer that forms on its surface $[7,10,11]$. More recently, crack self-healing characteristics have also been reported during oxidation of $\mathrm{Ti}_{2} \mathrm{AlC}$ and $\mathrm{Ti}_{3} \mathrm{AlC}_{2}[12,13]$.

Based on all the studies carried out over the past 60 years, only certain M elements can be combined with certain A elements to form MAX phases. For instance, Al containing MAX phases can only have $\mathrm{Ti}, \mathrm{V}, \mathrm{Cr}, \mathrm{Nb}$ and $\mathrm{Ta}$ as their $\mathrm{M}$ elements. Conversely, Mo, Hf, Zr, and others do not form Al-containing MAX phases. Furthermore, almost all solid solution MAX phases synthesized to date follow similar rules. There are few exceptions wherein a solid solution contains a M element, that does not generally bond to $\mathrm{Al}$, such as $\mathrm{Zr}$ in $\left(\mathrm{Nb}_{0.8}, \mathrm{Zr}_{0.2}\right)_{2} \mathrm{AlC}$ [14], and $\left(\mathrm{Nb}_{0.6}, \mathrm{Zr}_{0.4}\right)_{2} \mathrm{AlC}$ [15], 
and $\mathrm{Mn}$ in $\left(\mathrm{Cr}_{0.7}, \mathrm{Mn}_{0.3}\right)_{2} \mathrm{GaC}$ [16]. In both examples the mass fraction of the non-Al bonding $\mathrm{M}$ element is less that 0.5 of the total M-content.

Recently, Liu et al. reported on synthesizing of $\mathrm{Cr}_{2} \mathrm{TiAlC}_{2}$, from $\mathrm{Cr}_{2} \mathrm{AlC}$ and $\mathrm{TiC}$ [17]. Based on their neutron diffraction data, they concluded that the Cr-layers sandwiched the Ti-layers in a $\mathrm{M}_{3} \mathrm{AX}_{2} \mathrm{MAX}$ phase structure. Even more recently, Caspi et al. used high-resolution neutron diffraction to show that when $n=2$, in the $\left(\mathrm{Cr}_{0.5} \mathrm{~V}_{0.5}\right)_{\mathrm{n}+1} \mathrm{AlC} \mathrm{C}_{\mathrm{n}}$ system, the $\mathrm{V}$ and $\mathrm{Cr}$ atoms showed a strong tendency to ordering, with V only occupying the middle layer. Said otherwise, the 2a (000) sites were fully occupied by vanadium [18].

Of special interest to this work are Mo-containing MAX phases. To date the only known Mo-containing MAX phase was $\mathrm{Mo}_{2} \mathrm{GaC}$ [19]. In this study, for the first time, we report on a new Mo-containing ordered MAX phase, $\mathrm{Mo}_{2} \mathrm{TiAlC}_{2}$. In this phase, which is isostructural with $\mathrm{Ti}_{3} \mathrm{SiC}_{2}[4,20]$, the $\mathrm{Ti}$ atoms are sandwiched between two Mo-layers that in turn are adjacent to the Al planes resulting in a Mo-Ti-Mo-Al-Mo-Ti-Mo stacking order. The C-atoms are in between the Mo and Ti layers.

To synthesize this compounds elemental powders of Mo, Ti, Al and graphite (all from Alfa Aesar, Ward Hill, MA), with mesh sizes of -250, -325, -325 and -300 , respectively, were mixed in the molar ratio of Mo:Ti:Al:C 2:1:1.1:2 with zirconia milling balls, in plastic jars, for $18 \mathrm{~h}$. The powder mixture was then placed in a covered alumina crucible and heated at a rate of $5^{\circ} \mathrm{C} / \mathrm{min}$ to $1600{ }^{\circ} \mathrm{C}$ and held for $4 \mathrm{~h}$ under flowing argon (Ar). After furnace cooling, the slightly sintered porous compact was milled into a fine powder using a TiN-coated milling bit. 
$\mathrm{X}$-ray diffraction (XRD) was carried out on a diffractometer (Rikagu Smartlab, Tokyo, Japan), using step scans of $0.02^{\circ}$ in the $3^{\circ}-120^{\circ} 2$ theta range with a step time of 7 $\mathrm{s}$ with a $10 \times 10 \mathrm{~mm}^{2}$ window slit. Scans were made with $\mathrm{Cu}-\mathrm{K} \alpha$ radiation $(40 \mathrm{KV}$ and 44 $\mathrm{mA})$. Ten wt.\% silicon powder was added to the sample powder for XRD as an internal standard to calibrate the diffraction angles and instrumental peak broadening.

The XRD diffractograms were analyzed by the Rietveld refinement method, using the FULLPROF code [21, 22]. Refined parameters were: five background parameters, scale factors from which relative phase fractions are evaluated, $X$ and $Y$ profile parameters for peak width, lattice parameters (LPs) and atomic positions for all phases. High resolution scanning electron microscopy (HRSTEM) and X-ray energy dispersive spectroscopy (EDX) were carried out with the a double corrected FEI Titan3 60-300 operated at $300 \mathrm{kV}$, equipped with the Super-X EDX system. Selected area electron diffraction (SAED) characterization was performed using a FEI Tecnai G2 TF20 UT instrument equipped with a field emission gun runs at a voltage of $200 \mathrm{kV}$ and a point resolution of $0.19 \mathrm{~nm}$.

The specimens were prepared by embedding the MAX powder in a Ti grid, reducing the Ti-grid thickness down to $50 \mu \mathrm{m}$ via mechanical polishing and finally $\mathrm{Ar}+$ ion milling to reach electron transparency.

Figure 1a shows the XRD pattern obtained from the powder. Each peak is labeled on the pattern. Figure $1 \mathrm{~b}$ compares the experimental XRD pattern (black) with the calculated pattern obtained from the Rietveld analysis (red) from $2 \theta=21$ to $120^{\circ}$. The difference between the two is shown in (blue). The $\chi^{2}$ value was 2.44 , which shows the good agreement between model and measured data. The sample was found to be a 
predominately pure $\mathrm{Mo}_{2} \mathrm{TiAlC}_{2}$ phase. $\mathrm{Mo}_{2} \mathrm{TiAlC}_{2} a$-LP and $c$-LP were calculated from the refinement to be $2.99703(4)$ and $18.6608(3) \AA$, respectively.

Small peaks of a $\mathrm{M}_{2} \mathrm{AX}$ phase were also identified as the only impurity in the powder. A solid solution (MoTi) ${ }_{2} \mathrm{AlC}$ showed a very good fit with it. The (MoTi) ${ }_{2} \mathrm{AlC} a-$ and $c$-LPs were calculated from the refinement to be 3.021(5) and 11.756(4) $\AA$, respectively. The reported uncertainties of all structural values determined from Rietveld refinement are the uncertainties of the refinement process and are mainly of statistical origin. From the refined LPs of the internal Si standard, we evaluate the systematic uncertainty to be $<0.01 \%$. In $\mathrm{Mo}_{2} \mathrm{TiAlC}_{2}$, the refinement calculated z-coordinate for Mo at the $\mathrm{x}, \mathrm{y}$ coordinates of $(2 / 3,1 / 3)$ was $0.13327(6)$ and for $\mathrm{C}$ at $\mathrm{x}, \mathrm{y}$ coordinates of $(1 / 3$, 2/3) was 0.0691(5). In (MoTi) ${ }_{2} \mathrm{AlC}$ the z-coordinate for M (Mo and Ti) at the $\mathrm{x}, \mathrm{y}$ coordinates of $(1 / 3,2 / 3)$ was $0.069(2)$.

Given the 2:1 ratio of Mo:Ti and based on the recent work showing ordering of the $\mathrm{M}$-atoms in $\mathrm{Cr}_{2} \mathrm{TiAlC}_{2}$ [17], it was reasonable to assume that this phase was ordered as well. A schematic of such a unit cell is shown as an inset in Fig. 1. HRTEM images of a sample along the $[11 \overline{2} 0]$ zone axis with its SAED are shown in Figs. $2 \mathrm{a}$ and $\mathrm{c}$, respectively. Figure $2 \mathrm{~d}$ shows the SAED along the [1 $\overline{100]}$ zone axis. The $a$ - and $c$-LP were measured from SAED images to be 2.93(3) and 18.9(7) $\AA$, both values in good agreement with those measured from the XRD patterns.

Figure $2 b$ is the overlap of Fig. 2a and the total EDX mapping, in which the Mo, $\mathrm{Ti}$ and $\mathrm{Al}$ atoms are shown in blue, green and red, respectively. Based on this map it is clear that every green, or Ti, layer is sandwiched between two blue, or Mo, layers. Figure 2e shows an EDX line scan along the $[11 \overline{2} 0]$ axis of the micrograph shown in Fig. $2 \mathrm{f}$. 
The Mo, Ti and Al lines have the same coloring as in Fig. 2b. In other words, the line scan confirms the ordering sequence.

Based on the totality of our results it is thus reasonable to conclude that $\mathrm{Mo}_{2} \mathrm{TiAlC}$, is highly ordered, with the Mo layers sandwiching the Ti- layers in a structure that is iso-structural with $\mathrm{Ti}_{3} \mathrm{SiC}_{2}$ [20]. In this compound the layer sequence - excluding C - is: Al-Mo-Ti-Mo-Al-Mo-Ti-Mo etc.

It is worth noting that $(\mathrm{MoTi})_{2} \mathrm{AlC}$ was the only other phase detected in the XRD patterns. This $\mathrm{M}_{2} \mathrm{AX}$ phase is thus also a new solid solution in the MAX phase family that to date has not been reported. However, given its chemistry, it is unlikely that this MAX phase is ordered. This comment notwithstanding, more work should be dedicated to synthesizing and characterizing this new phase.

The importance of this work lies beyond the compounds made herein, since it opens up a new avenue to make MAX phases with bonds that had not been previously observed. For example, in this work the MAX phase created contains Mo-Al bonds. As noted in the introduction, before this work the only Mo-containing MAX phase was comprised of Mo-Ga-Mo layers. We note in passing that $\mathrm{Mo}_{3} \mathrm{AlC}_{2}$ does not exist and it follows that the Ti layer is crucial in stabilizing it and lowering its energy.

The fact that Mo is on the outer layers of $\mathrm{M}$ sites might lead to different properties for this new phase than a regular Ti-Al containing solid solution. The implications for totally new MXenes chemistries has also not escaped us and will be the subject of a separate forthcoming paper. 


\section{Acknowledgement}

This work was partially supported by the Army Research Office (W911NF-11-1-

0525). J.H. and MW.B. acknowledges the support from the SSF synergy grant

FUNCASE Functional Carbides and Advanced Surface Engineering. The Linköping

Electron Microscopy Laboratory was supported by the Kunt and Alice Wallenberg

Foundation. 


\section{References}

[1] M.W. Barsoum, M. Radovic, Annual Review of Materials Research, 41 (2011) 195227.

[2] P. Eklund, M. Beckers, U. Jansson, H. Högberg, L. Hultman, Thin Solid Films, 518 (2010) 1851-1878.

[3] M.W. Barsoum, MAX Phases: Properties of Machinable Ternary Carbides and Nitrides, John Wiley \& Sons, 2013.

[4] M.W. Barsoum, T. ElRaghy, J Am Ceram Soc, 79 (1996) 1953-1956.

[5] M.W. Barsoum, D. Brodkin, T. ElRaghy, Scripta Materialia, 36 (1997) 535-541.

[6] M.W. Barsoum, M.C. Flemings, E.J. Kramer, S. Mahajan, P. Veyssiere, In: Encyclopedia of materials science and technology, (2006).

[7] D.J. Tallman, B. Anasori, M.W. Barsoum, Materials Research Letters, 1 (2013) 115125.

[8] B. Anasori, E.a.N. Caspi, Y. Elraheb, M.W. Barsoum, Journal of Alloys and Compounds, 580 (2013) 550-557.

[9] D.J. Tallman, M. Naguib, B. Anasori, M.W. Barsoum, Scripta Materialia, 66 (2012) 805-808.

[10] M. Sundberg, G. Malmqvist, A. Magnusson, T. El-Raghy, Ceramics International, 30 (2004) 1899-1904.

[11] X.H. Wang, Y.C. Zhou, Oxidation of Metals, 59 (2003) 303-320.

[12] G.M. Song, Y.T. Pei, W.G. Sloof, S.B. Li, J.T.M. De Hosson, S. van der Zwaag, Scripta Materialia, 58 (2008) 13-16.

[13] H. Yang, Y. Pei, J. Rao, J.T.M. De Hosson, Journal of Materials Chemistry, 22 (2012) 8304-8313.

[14] M. Naguib, G. Bentzel, J. Shah, J. Halim, E. Caspi, J. Lu, L. Hultman, M. Barsoum, Materials Research Letters, (2014) 1-8.

[15] H. Nowotny, P. Rogl, J.C. Schuster, Journal of Solid State Chemistry, 44 (1982) 126133.

[16] A. Mockute, J. Lu, E.J. Moon, M. Yan, B. Anasori, S.J. May, M.W. Barsoum, J. Rosen, Materials Research Letters, (2014) 1-7.

[17] Z. Liu, E. Wu, J. Wang, Y. Qian, H. Xiang, X. Li, Q. Jin, G. Sun, X. Chen, J. Wang, M. Li, Acta Mater, 73 (2014) 186-193.

[18] E.N. Caspi, P. Chartier, F. Porcher, F. Damay, T. Cabioc'h, Materials Reseach Letters, (2014) 1-7.

[19] L.E. Toth, Journal of the Less Common Metals, 13 (1967) 129-131.

[20] W. Jeitschko, H. Nowotny, Monatshefte für Chemie, 98 (1967) 329-337.

[21] H.M. Rietveld, Journal of Applied Crystallography, 2 (1969) 65-71.

[22] J. Rodríguez-Carvajal, Physica B: Condensed Matter, 192 (1993) 55-69. 


\section{Figure Captions}

Figure 1. (a) Powder XRD patterns of Mo2TiAlC2, black rectangles show location of Si powder peaks, added as an internal standard; Inset shows schematic of Mo2TiAlC2 unit cell. (b) Powder XRD patterns of Mo2TiAlC2, observed pattern (black crosses), Rietveld generated pattern (red line) and difference between the two (blue line). The black and blue ticks below the pattern represent the peak positions of the Mo2TiAlC2 phase, and Si phase, respectively.

Figure 2. (a) HRSTEM of $\mathrm{Mo}_{2} \mathrm{TiAlC}_{2}$ along the [11 $\left.\overline{2} 0\right]$ zone axis, (b) the overlap of EDX mapping on (a) showing the Mo atoms in blue, Ti atoms in green and $\mathrm{Al}$ atoms in red, (c) and (d) SEAD of $\mathrm{Mo}_{2} \mathrm{TiAlC}_{2}$ along the [11 $\left.\overline{2} 0\right]$ and [1 $\left.\overline{1} 00\right]$ zone axes, respectively, (e) EDX line scan profile of Mo (blue circles), Ti (green squares), and Al (red triangles), (f) STEM of the EDX line scanned region the results of which are shown in $(\mathrm{e})$. 

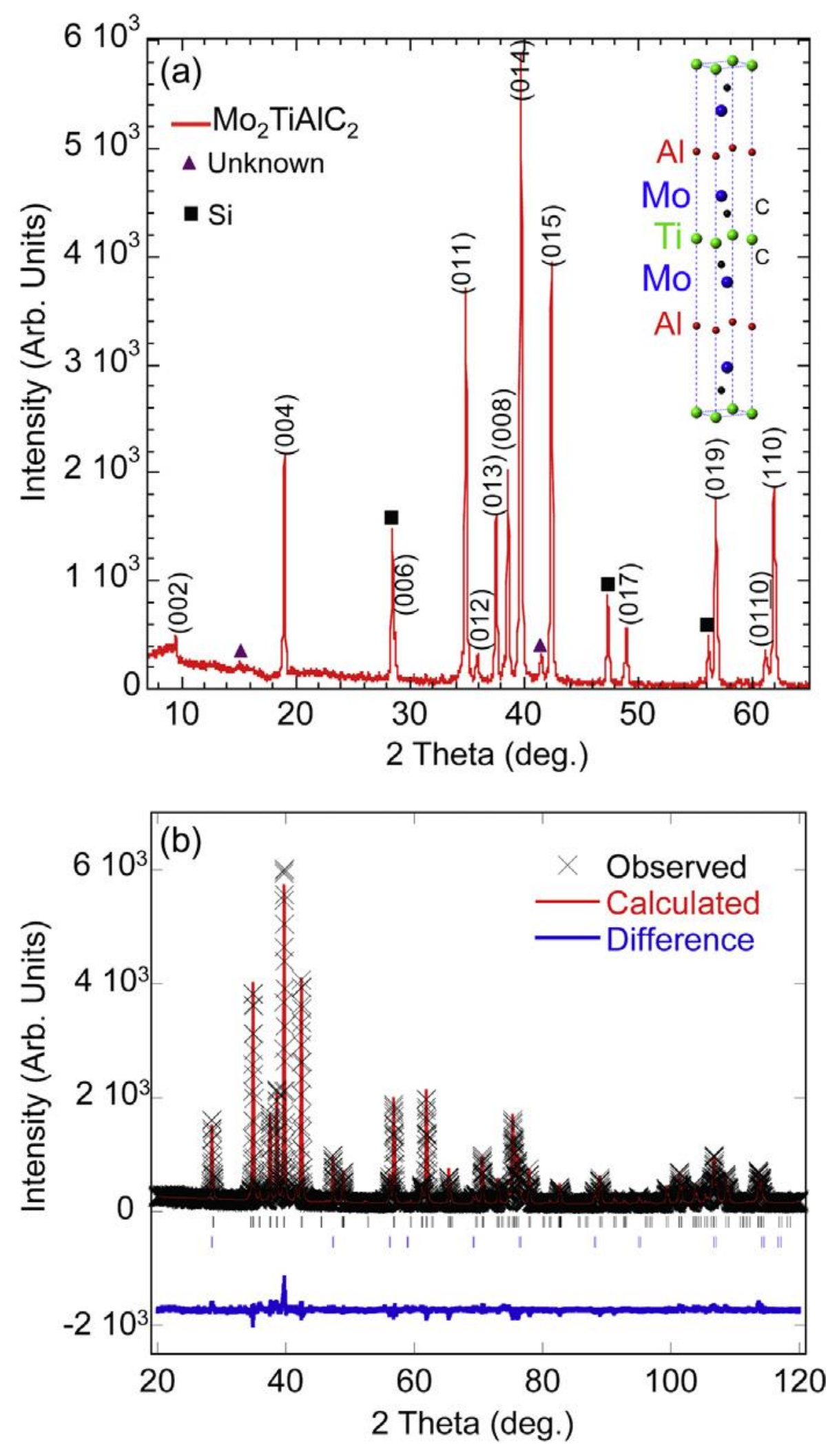

Fig. 1 

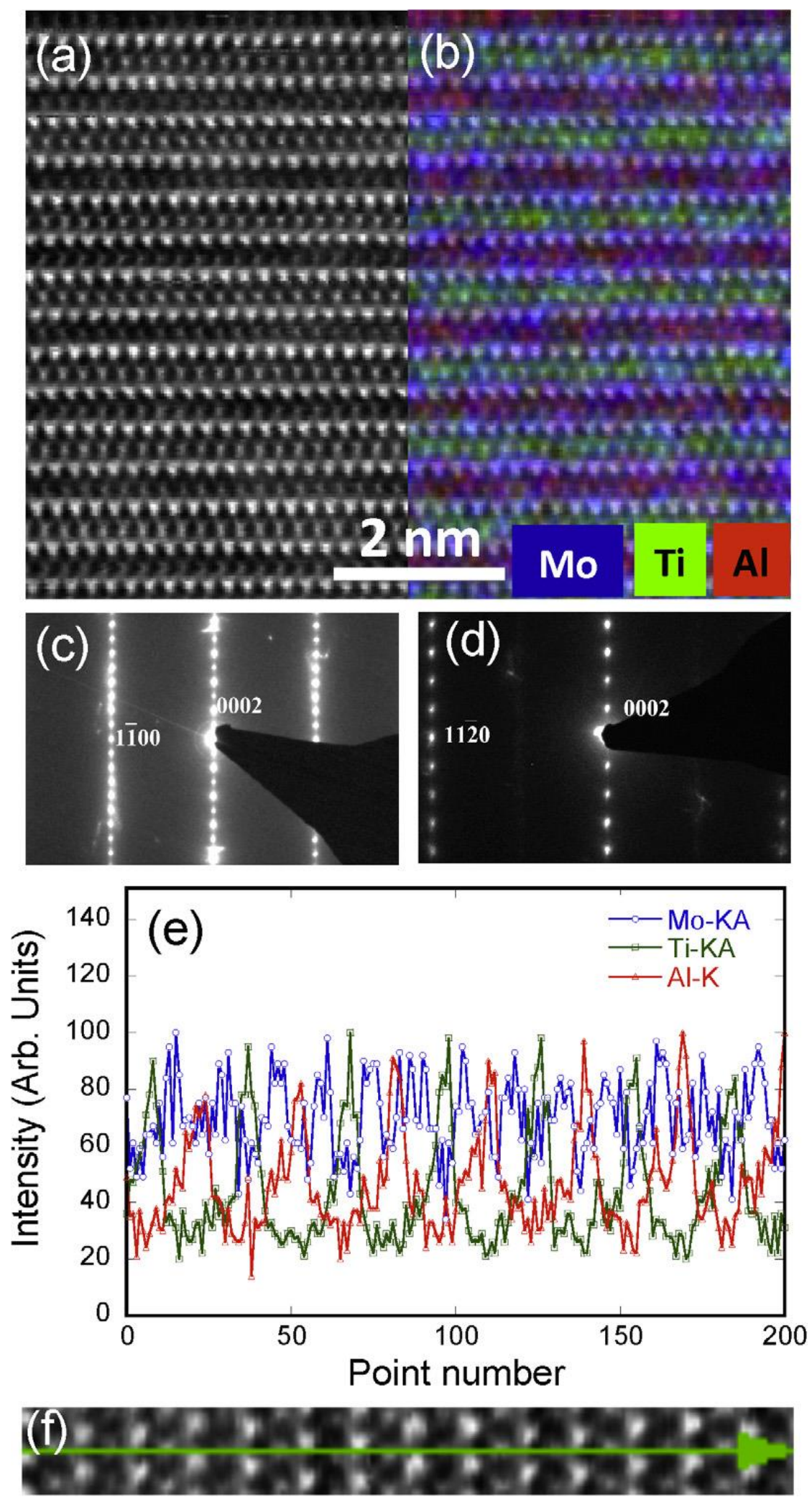

Fig. 2 